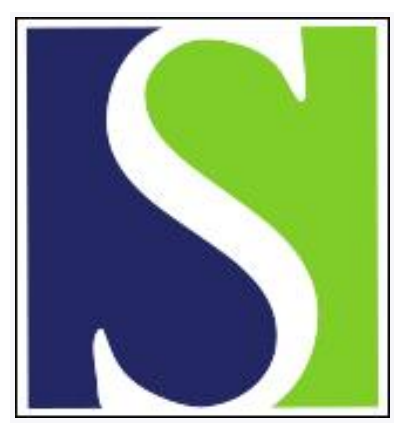

Scand J Work Environ Health 1986;12(5):494-498

https://doi.org/10.5271/sjweh.2117

Issue date: Oct 1986

Changes in water vapor loss from the skin of metal industry workers monitored during exposure to oils.

by Coenraads PJ, Lee J, Pinnagoda J

This article in PubMed: www.ncbi.nlm.nih.gov/pubmed/2947320

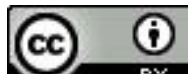




\title{
Changes in water vapor loss from the skin of metal industry workers monitored during exposure to oils
}

\author{
by Pieter-Jan Coenraads MD, MPH, James Lee, MSc, PhD, Jaliya Pinnagoda, BSc ${ }^{1}$
}

\begin{abstract}
COENRAADS P-J, LEE J, PINNAGODA J. Changes in water vapor loss from the skin of metal industry workers monitored during exposure to oils. Scand $J$ Work Environ Health 12 (1986) 494-498. Vapor loss (VL) from nonsweating skin (SVL), a surrogate measure for transepidermal water passage, was ascertained electronically from 54 newly recruited metal workers. A weekly measurement was taken for 12 weeks from each worker in the three groups studied: 17 unexposed workers, 13 workers exposed to water-soluble oils and 24 workers exposed to straight mineral oil. During the 12 -week period four workers in the group exposed to mineral oil developed contact dermatitis, with a markedly increased SVL. Among the 50 workers whose skin remained normal, the mean initial SVL was $6.8 \mathrm{~g} \cdot \mathrm{m}^{-2} \cdot \mathrm{h}^{-1}$ for the back of the hand, 4.4 for the extensor, and 4.7 for the volar forearm. There was a slight but nonsignificant increase in all three SVL levels in the group exposed to water-soluble oils as compared to the unexposed group. In the group exposed to mineral oils the SVL of the extensor and volar forearm rose to a significantly higher level as compared to those of the unexposed group. This difference persisted after statistical adjustment for age, sex, ethnic group, and initial SVL level. These findings indicate that SVL measurement has potential as a monitoring parameter for workers at risk of occupational contact dermatitis.
\end{abstract}

Key terms: contact dermatitis, follow-up, forearms.

The skin forms an effective barrier against external agents, as well as internal body fluids, especially water. This barrier is located in the stratum corneum. In several studies this barrier has been regarded as a complex membrane through which the diffusion of various chemicals has been studied in vivo and in vitro (12). Aside from sweating, a small quantity of water also permeates through the stratum corneum in accordance with Fick's law of diffusion and evaporates from the skin. This process is commonly known as transepidermal water loss (4). Techniques for measuring this loss have been described by several authors $(10$, 15 ), and it has been demonstrated to increase in cases of damaged or diseased skin (13). Sweating is supposed to be suppressed during these measurements in vivo, but, as some authors (15) assume that a small quantity of water vapor from the sweat glands may contaminate the measurements, the term skin vapor loss (SVL) is generally used.

Contact dermatitis of the hands and forearms is a widespread occupational health problem. Although more-refined patch testing methods have increased the detection rate of (delayed-type) allergic contact dermatitis, most cases belong to the category of irritant contact dermatitis. This type is assumed to be the result of an accumulation of exposure to relatively weak toxic stimuli, which leads via a stage of clinically in-

\footnotetext{
1 Department of Social Medicine and Public Health, National University of Singapore, Kent Ridge, Singapore.
}

Reprint requests to: Dr P-J Coenraads, Occupational Dermatology, University Hospital, PO Box 30.001, 9700 RB Groningen, The Netherlands. visible damage to manifest "cumulative insult" dermatitis (7). Inherent skin toxicity of various substances can be assessed in animal tests and is theoretically also possible in humans. But, other than patch testing for the evaluation of allergic contact dermatitis, there are no techniques that can determine which specific substance causes the irritant dermatitis in an individual patient. Nor are there techniques that can predict an individual's skin susceptibility to mild toxic (irritant) agents.

Irritant contact dermatitis is a well documented problem in the metal industry, and it is usually ascribed to exposure to mineral and water-soluble oils used as lubricants or coolants in the process of grinding, drilling, lathing, etc. Occasionally allergic contact dermatitis caused by some oil additives is diagnosed, but in general the dermatitis is of the irritant type, of which the exact cause is unknown (11). The problem seems to be more common when soluble oils are used, and surface-active constituents are assumed to be responsible.

This study addresses the postulate that there is an increase in the level of transepidermal water loss in parallel with stratum corneum damage in persons at risk of developing irritant contact dermatitis. Accordingly, SVL data were collected from workers in a large metal factory where contact dermatitis was a frequently encountered problem. The factory recruited new employees almost every week. From the first to the twelfth week of employment these employees were monitored weekly for signs of skin disease and were also measured in terms of SVL (as an approximation for transepidermal water loss) from the hands and forearms. The specific aim of the investigation was to determine to what extent occupational exposure to oils affects 
SVL levels over time, especially at the worksite where, in the past, the most cases of dermatitis occurred.

\section{Subjects and methods}

The study was conducted between September 1984 and May 1985 and was confined to all workers newly recruited for the metal parts production departments (ie, not the assembly lines) in a large Singapore plant of an American-based company. There was high employee turnover, and almost every week new workers were recruited who, after having given their informed consent, were entered into the study. Thus only previously unexposed workers were studied. The workers belonged to the following departments:

Press stamping and drilling: These workers $(\mathrm{N}=17)$ were not exposed to oils except for some contamination of the hands by specks of oil or grease; they formed the unexposed comparison group.

Drilling: These workers $(\mathrm{N}=6)$ rotated between the operation of "dry" machines and machines that periodically splash the hands with $\operatorname{Trimsol}^{\circledR}$, a watersoluble oil.

Grinding: These workers $(N=7)$ rotated between dry machine work and oily tasks in which the hands were intermittently in contact with $\mathrm{Cindol}^{\circledR}$, a watersoluble oil.

Cutting and lathing: The hands and forearms of these workers $(\mathrm{N}=24)$ were continuously exposed to Castrol Magna $68^{\circledast}$, a straight mineral oil. In the past, most of the skin problems occurred in this department.

The allocation of new workers to one of these departments was decided by the management and was not influenced by this study. In principle, there were no transfers from one department to another. Since the type of work and the oils in the drilling and grinding departments were similar, the workers in these departments were combined. Thus, three exposure groups (unexposed, exposed to water-soluble oils, and exposed to mineral oil) were created, of which only the 50 members who did not develop dermatitis have been included in the present study. The composition of the oils, in particular regarding the emulsifiers, could not be disclosed by the suppliers.

After having been assigned to a department, the new worker underwent job training for several days, during which the first measurement (initial SVL values) for this study was conducted. Other information collected included age, sex, ethnicity, previous job, history of skin disease and current skin problems, history of atopy, and recording of SVL on the dorsal side of the right hand and on the extensor and volar surfaces of the right forearm, $7 \mathrm{~cm}$ from the wrist skinfold. Three patch tests were done on the volar side of the right forearm, each with one of the aforementioned oils undiluted. The following day the patch tests were removed and after $1 \mathrm{~h}$ the SVL was measured at the site of each patch.

Each worker was then monitored for 12 weeks. The SVL measurements were repeated at the same sites every week, usually on Wednesdays or Thursdays. At the same time the hands and arms were inspected by a dermatologist (PJC) for early signs of rashes. Skin temperature and ambient room temperature were also recorded during the weekly follow-up sessions for each individual. When a worker was absent, a new attempt was made the following days. When he remained absent for the rest of the week or when he was on the late nightshift, a missing observation was recorded.

All measurements were done in the nurse's office of the factory. Subjects on the day and evening shift were scheduled to come from their worksite at $15-\mathrm{min}$ intervals. Before being admitted to the measurement room, they were given a 10 -min rest period in a cool waiting room in order to minimize any sweating. If the measurements indicated sweating, the rest period was prolonged. The whole factory, including the worksites, was air-conditioned $24 \mathrm{~h}$ a day, the ambient relative indoor humidity being around $55 \%$. In the waiting room the temperature was around $21-22^{\circ} \mathrm{C}$, the measurement room was usually $1-2^{\circ} \mathrm{C}$ warmer. Due to the geographic location, outdoor seasonal variation in temperature and humidity was negligible.

SVL was measured electronically in grams of water - $\mathrm{m}^{-2} \cdot \mathrm{h}^{-1}$ by the vapor pressure gradient method described elsewhere $(10,16)$ and with the use of an evaporimeter (EP1) with a probe (Servomed, Stockholm). The instrument was connected to a graph recorder (SR6211, Graphtech, Tokyo). Each skin site was measured continuously for about $5 \mathrm{~min}$, the graph therefore being allowed to become stabilized as a horizontal line. This horizontal traject was taken as the SVL reading for the skin site concerned. To avoid measurement errors caused by air currents, the SVL readings were taken inside a transparent box, into which the subject had placed his hand and part of his forearm. This box had sufficient ventilation openings to avoid any build-up of heat and water vapor from the subject's skin. Moreover, the operator's hand, which held the probe, was gloved. Skin temperature was recorded from the extensor side of the right forearm, $7 \mathrm{~cm}$ from the wrist, by means of an infrared sensitive probe (Thermophil M202, Ultrakust, Federal Republic of Germany). For patch testing Finn-chambers were used (Epitest, Helsinki).

The primary aim of the statistical analysis was to compare the trend of each SVL measurement (back of the hand and extensor and volar side of the arm) over time in weeks among the three exposure groups. First, the trend of the crude mean SVL over time was depicted for each group, accompanied by a separate regression analysis (14) of the SVL on time for each group (figure 1). However, a comparison of the crude mean SVL among the three exposure groups was potentially confounded by race, sex, age, and initial 
SVL values (table 1). Accordingly, statistical adjustment for these potential confounding variables was carried out by multiple covariance analysis (14), using the GLM procedure described by SAS (3) (figure 2).

\section{Results}

Of the 54 workers included in the study sample, four developed occupational dermatitis. Details about their

Table 1. Comparison of race, sex, age, and mean initial vapor loss from the skin of the 50 subjects who did not develop dermatitis in the three exposure groups.

\begin{tabular}{|c|c|c|c|}
\hline & $\begin{array}{l}\text { Unexposed } \\
(N=17)\end{array}$ & $\begin{array}{l}\text { Exposed } \\
\text { to water- } \\
\text { soluble oils } \\
(N=13)\end{array}$ & $\begin{array}{c}\text { Exposed } \\
\text { to mineral } \\
\text { oils } \\
(N=20)\end{array}$ \\
\hline $\begin{array}{l}\text { Race }(\%) \\
\text { Chinese } \\
\text { Malay } \\
\text { Others }\end{array}$ & $\begin{array}{l}23 \\
65 \\
12\end{array}$ & $\begin{array}{l}46 \\
54 \\
-\end{array}$ & $\begin{array}{l}35 \\
55 \\
10\end{array}$ \\
\hline Males (\%) & 24 & 46 & 100 \\
\hline Mean age (years) & 28 & 25 & 28 \\
\hline $\begin{array}{l}\text { Mean initial vapor } \\
\text { loss }\left(g \cdot m^{-2} \cdot h^{-1}\right) \\
\text { Hand } \\
\text { Forearm } \\
\quad \text { Extensor surface }\end{array}$ & $\begin{array}{l}6.9 \\
4.2\end{array}$ & $\begin{array}{l}6.2 \\
4.2\end{array}$ & $\begin{array}{l}7.1 \\
4.6\end{array}$ \\
\hline Volar surface & 4.6 & 4.8 & 4.7 \\
\hline
\end{tabular}
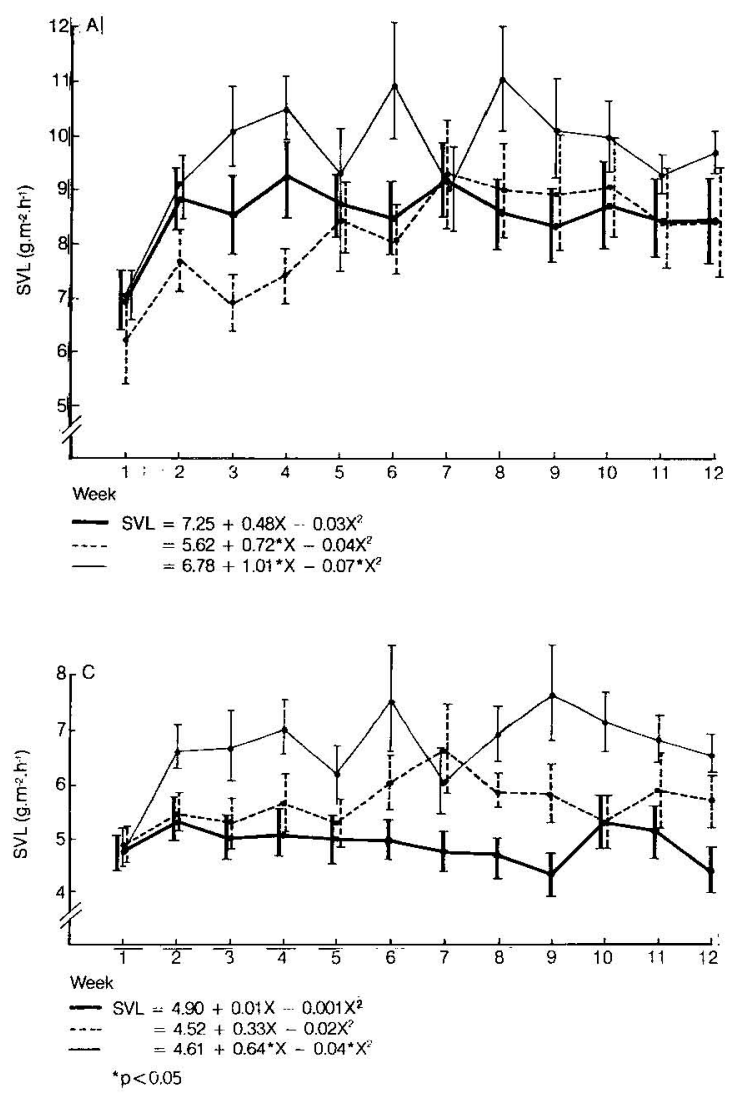

SVL values, which were, on the average, markedly higher than those of the workers without dermatitis, will be described in a separate communication, of which a summary has already been published (2). The present analysis includes only the 50 workers for whom no dermatitis was detected.

Table 1 shows the distribution of race, sex, mean age, and mean initial SVL values of subjects in the three exposure groups. There was a slight preponderance of Chinese workers in the group exposed to water-soluble oils and Malay workers in the unexposed group. A considerable imbalance of male workers also occurred in the three groups with the lowest proportion in the unexposed group and highest in the mineraloil exposed group. On the other hand, there was no marked age difference in the three groups.

The crude mean (plus and minus one standard error) of the SVL among the three exposure groups at each week of follow-up is presented in figure 1. As expected, there was no discernible difference in any of the three base-line (ie, week 1) SVL values among the three exposure groups. The mean SVL ranged from 6.2 to $7.1 \mathrm{~g} \cdot \mathrm{m}^{-2} \cdot \mathrm{h}^{-1}$ for the back of the hand $(\mathrm{p}>0.05)$, from 4.2 to $4.6 \mathrm{~g} \cdot \mathrm{m}^{-2} \cdot \mathrm{h}^{-1}$ for the extensor side of the forearm ( $\mathrm{p}>0.05)$, and from 4.6 to $4.8 \mathrm{~g} \cdot \mathrm{m}^{-2}$ $\cdot h^{-1}$ for the volar side of the forearm $(\mathrm{p}>0.05)$. Figure 1 shows clearly that the SVL values among the three exposure groups began to diverge from the sec-

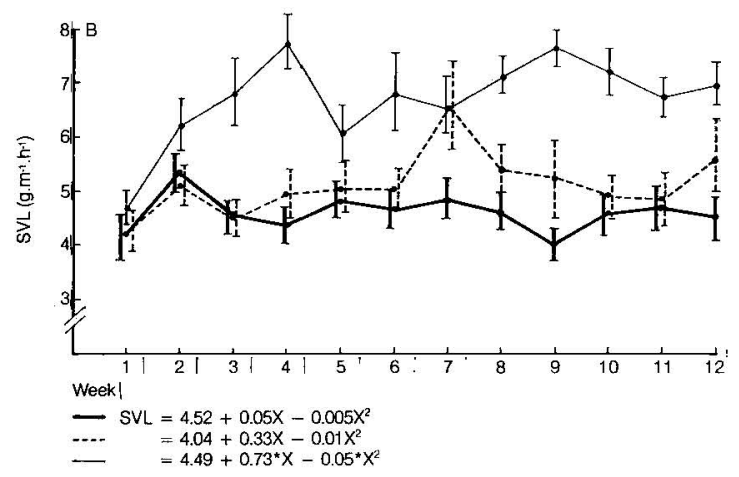

Figure 1. Mean skin vapor loss (SVL) and the standard error of the mean according to time in weeks for the back of the hand (A) and the extensor (B) and volar (C) surfaces of the forearm of the workers who did not develop dermatitis. $\left(-\frac{1}{=}\right.$ unexposed group, $\cdots=$ group exposed to water-soluble oils, = group exposed to mineral oils) 
ond week on, workers in the mineral-oil exposed group having the highest, those in the group exposed to watersoluble oils the intermediate, and those in the unexposed group the lowest values.

On the extensor and volar sides of the forearm, most of the SVL means of the group exposed to mineral oil were significantly higher $(\mathrm{p}<0.05)$ than the corresponding means of the unexposed group; none of the SVL means for the back of the hand were significantly different between these two groups. Although the group exposed to water-soluble oils tended to show higher mean SVL readings than the unexposed group, the difference between the two groups was not significant at most of the measurement times.

Fitted regression equations of the SVL readings (SVL $=$ dependent variable) on time in weeks ( $\mathrm{X}$ and $\mathrm{X}^{2}=$ regressor variables) for each skin site and each exposure group are also presented in figure 1. As the trend of SVL on time appeared to be nonlinear, second-degree polynomial regression equations were obtained by the least square method. The objective was to determine whether the relationship of SVL on X was statistically linear and whether the relationship was also statistically nonlinear, ie, whether the $\beta$ of the SVL on $\mathrm{X}^{2}$ was significant. (Note that the trend of the SVL readings on time for each skin site was statistically nonlinear, ie, the regression coefficient of the quadratic term $\left(\mathrm{X}^{2}\right)$ was statistically significant, only for the group exposed to mineral oil.) There was no significant relationship for SVL on time for any of the skin sites in the unexposed group, but there was one for the back of the hand in the two exposed groups, and for the extensor side and volar side of the forearm in the group exposed to mineral oil.

Figure 2 presents the same type of graphs but based on statistically adjusted means of the SVL. Each mean SVL from week 2 on was adjusted for the following potential confounding factors: base-line SVL (ie, SVL reading at week 1), age, sex, and ethnicity. These graphs show the same pattern as in figure 1 , ie, a significantly elevated mean SVL for the group exposed to mineral oil. The degree of confounding by the aforementioned factors was slight since the shapes of the graphs in figure 2 were not discernibly different from those in figure 1.

\section{Discussion}

The data in this study demonstrated an increase in SVL over time, and this increase was attributed to exposure to oils. The effect, whether due to toxic damage or an altered hydration state of the stratum corneum, was considerably more pronounced with exposure to mineral oil than with water-soluble oil. In the past, most cases of dermatitis were reported among the workers employed at the worksite with mineral-oil exposure, and the four cases detected during this study also belonged to the group exposed to mineral oil. These findings suggest that SVL measurements, at least
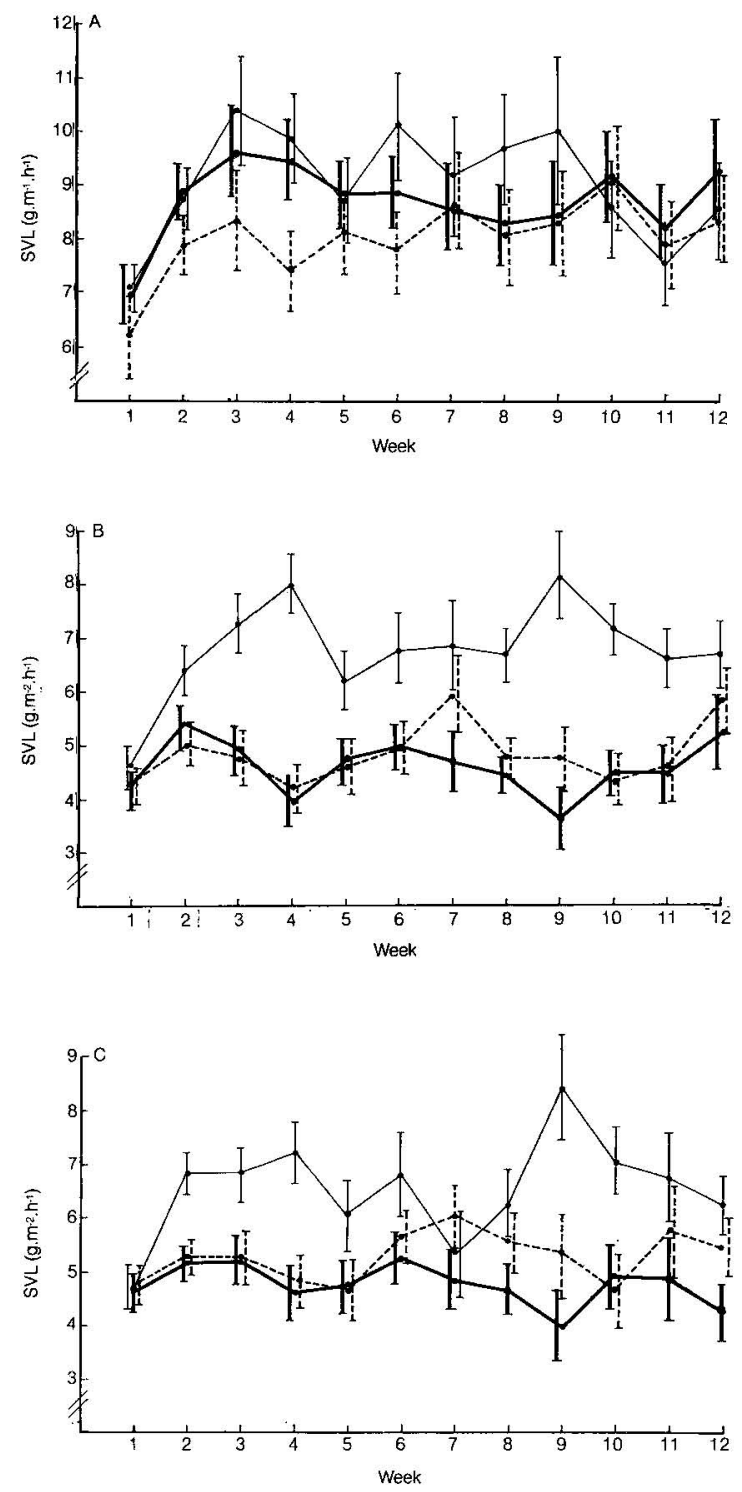

Figure 2. Mean skin vapor loss (SVL) and the standard error of the mean, statistically adjusted for race, sex, age, and initial SVL values, according to time in weeks for the back of the hand (A) and the extensor (B) and volar (C) surfaces of the forearm of the workers who did not develop dermatitis. (- $=$ unexposed group, $-\cdot=$ group exposed to water-soluble oils, = group exposed to mineral oils)

on a group basis, could be used to detect an effect of a chemical exposure (eg, oil) on clinically normal skin. In other words SVL readings could be used in the monitoring of exposed workers at risk of occupational contact dermatitis.

These data further suggest that the effect of exposure to mineral oils can be detected after two to three weeks and that it tends to stabilize at a certain level. This result is understandable since a further increase would eventually be accompanied by overt dermatitis. Obviously in these workers a certain degree of adaptation takes place. The rise in SVL over the first few 
weeks in the unexposed group, which was the most pronounced at the back of the hand, may be explained by the fact that there was some contamination of the back of the hand from remnants of oils splashed around in very small amounts during press stamping. Also more vigorous cleaning of the skin with detergents after workshifts may have affected the skin barrier function.

In other studies, water-soluble oils have been shown to cause more dermatitis than mineral oils (6). This finding is contrary to the situation in the factory of our study where, in the past, there were fewer cases of dermatitis in the group exposed to water-soluble oils. In addition, in the present investigation, the mean SVL was not significantly increased in this group. This result may be explained by the fact that their exposure was intermittent, ie, less intense than in the mineraloil group, with rotation to tasks that imply "dry" machine work.

Earlier publications give formulas for the effect of skin temperature on SVL (8). In this study the SVL values were not corrected for skin temperature since it varied between $28-32^{\circ} \mathrm{C}$, which is too little variation to have any effect. Confounding by previous exposure to an "oily" job could not be taken into account in the calculations of the covariance-adjusted means (figure 2) since it pertained to only four persons. Although history of atopy has been shown to influence SVL (17), it was not entered for the same reason, ie, there was only one person. It is felt that there may well be more subjects with such a history, but that it was not detected during the history taking since many workers did not quite understand this concept because of language and cultural barriers.

In spite of successful attempts during the planning stage, the ambient temperature could not be kept at $20^{\circ} \mathrm{C}$ or below. At this temperature sweating is reportedly completely suppressed in a resting subject (1). It can be argued that the ambient temperature of $21-$ $22^{\circ} \mathrm{C}$ in the waiting room is sufficiently cool for the inhabitants of this tropical country where outdoor temperature never drops below $22^{\circ} \mathrm{C}$. The mean base-line SVL of the forearm, ie, at the beginning of exposure at week 1, compares well with values cited by other authors, summarized by vander Valk (16). However, the mean SVL values obtained in studies that included anticholinergic sweat-gland suppression $(1,5)$ were about $1 \mathrm{~g} \cdot \mathrm{m}^{-2} \cdot \mathrm{h}^{-1}$ lower than those in this investigation. It should be noted that all the cited studies were done in more ideal laboratory settings than this field trial in a factory.

There was considerable intrasubject variation of SVL in a number of subjects, and it was more pronounced in the exposed groups. It is tempting to ascribe this phenomenon to exposure alone, but inadequate control of emotional sweating may have played an important role. Future studies should incorporate a rapid and feasible local sweat suppression method which does not alter the barrier properties of the stratum corneum. The benzoyl ester of scopolamine hydrobromide may be a good candidate (9). Future studies should also extend follow-up and include larger sample sizes to insure collection of more cases of dermatitis than the four in this study. This procedure would permit the application of multiple logistic regression models to detect a level of SVL (independent variable) that is a good predictor of dermatitis risk (dependent variable).

\section{Acknowledgments}

We acknowledge the assistance of Mr SS Chan, L de Weerd, and $\mathrm{E}$ de Graaf in the data collection.

\section{References}

1. Baker H, Kligman AM. Measurement of transepidermal water loss by electrical hygrometry. Arch Dermatol 96 (1967) $441-452$.

2. Coenraads PJ, Pinnagoda J. Dermatitis and water vapor loss in metal workers. Contact Dermatitis 13 (1985) $347-348$.

3. Freund RJ, Littell RC. SAS for linear models. SAS Institute Inc, Cary NC 1981, pp 187-205.

4. Grice KA. Transepidermal water loss. In: Jarrett A, ed. Physiology and pathophysiology of the skin. Academic Press, London \& New York 1980, pp 2116-2146.

5. Johnson C, Shuster S. The measurement of transepidermal water loss. Br J Dermatol 81 (1969): suppl 4, 40-46.

6. Key MM, Ritter EJ, Arndt KA. Cutting and grinding fluids and their effects on the skin. Am Ind Hyg J 27 (1966) 423-427.

7. Malten KE. Thoughts on irritant contact dermatitis. Contact Dermatitis 7 (1981) 238-247.

8. Mathias CGT, Wilson DM, Maibach HI. Transepidermal water loss as a function of skin surface temperature. J Invest Dermatol 77 (1981) 219-220.

9. McMillan FSK, Reller HH, Synder FH. The antiperspirant action of topically applied anticholinergics. J Invest Dermatol 43 (1964) 363-377.

10. Nilsson GE. Measurement of water exchange through skin. Med Biol Eng Comput 15 (1977) 209-218.

11. Rycroft RJG. Soluble oil as a major cause of occupational dermatitis. Cambridge University, Cambridge 1982. (Doctoral thesis).

12. Scheuplein RJ, Blank IH. Permeability of the skin. Physiol Rev 51 (1971) 702-747.

13. Shahidullah M, Raffle EJ, Rimmer AR, Frain-Bell W. Transepidermal water loss in patients with dermatitis. Br J Dermatol 81 (1969) 722-730.

14. Snedecor GW, Cochran WG. Statistical methods. Sixth edition. Iowa State University Press, Ames, IA 1968, pp 438-443.

15. Thiele FAJ, Malten KE. Insensible water loss. Trans St John's Hosp Dermatol Soc 58 (1972) 199-217.

16. vander Valk PGM. Water vapour loss measurements on human skin. State University, Groningen (The Netherlands) 1984. (Doctoral thesis).

17. vander Valk PGM, Nater JP, Bleumink E. Vulnerability of the skin to surfactants in different groups of eczema patients and controls as determined by water vapor loss. Clin Exp Dermatol 10 (1985) 98-103.

Received for publication: 10 February 1986 